\title{
Problems and Prospects of Regional Mining Industry Digitalization
}

\author{
Tatiana Tyuleneva ${ }^{1}$ \\ ${ }^{1}$ T.F. Gorbachev Kuzbass State Technical University, Кафедра управленческого учета и анализа, \\ 650000 Kemerovo, 28 Vesennya st., Russian Federation
}

\begin{abstract}
One of the problems of modernizing the mineral resource clusters`socio-economic sphere is to increase the competitiveness of mining enterprises, which can be achieved by reducing costs, improving product quality, and ensuring production safety. The article describes the directions of mining industry digitalization, the advantages of implementing digital technologies in the process of forming the finished products ' cost and price, associated with increasing the reality of the resource base, optimizing the cost of materials and equipment, improving the system for predicting production failures, monitoring the implementation of the plan. The risks of using digital technology in mining enterprises due to insufficient automation of production processes, ensuring cybersecurity and staff qualifications are listed. In addition, there is a justification for the existing potential and identified threats, and the technologies used in the implementation of the federal and regional digitalization program or planned for use in the next year by enterprises of the Kuzbass coal mining industry, as well as the problems associated with their implementation are described.
\end{abstract}

\section{Introduction}

In the context of global competition the world coal market faces the same challenges as other economic entities: development in the context of increasing protectionism and overcapacity, improving production efficiency, reducing environmental impact, improving production safety, and developing human capital. The level of enterprise competitiveness is primarily determined by productivity and operational excellence in mining industry [1]. In this regard digitalization is becoming a determining factor that will allow organizations to remain competitive in the future. Accordingly, Russian mining industry needs its own advanced developments and scientific solutions to reach a new level of economic and social development. To this end, the Government of Russian Federation approved the "Digital economy of Russian Federation" Program in 2017, which implements the principles of economic feasibility and increasing the availability of energy infrastructure and distributed energy in order to ensure the digital transformation of the fuel and energy complex industries.

Issues of digitalization of the mining industry are relevant for Kemerovo region Kuzbass [2], the leading mining region of Russian Federation, where at the end of 2019, the 
regional program for digitalization of coal production "Clean coal - Green Kuzbass" was adopted.

\section{Theory of Experimental Research}

The main problems facing mining companies today are underestimated product estimates, rising costs, environmental challenges, project suspensions, declining global demand, and growing health and safety risks. Five main issues that need to be addressed in the near future are: improving production efficiency through the collection and reasonable use of data; introducing innovations related to the use of technologies and computer applications that are already actively used in other industries; expanded use of information technologies instead of technological optimization of previous methods; introduction of new technologies in connection with increasing requirements for environmental protection at the sites of extraction and processing of raw materials; introduction of methods for managing end-to-end processes and the use of instrumentation using engineering and application software, as well as platforms for collecting and displaying data from various sources [3].

Historically mining operations were divided into separate operational divisions (autonomous solutions) with minimal integration between mining, processing, and transport. Development from individual elements of linked value chains opens up new opportunities for change and provides a wide range of opportunities to find new effective solutions and achieve results, as well as to implement environmental projects or, in other words, to prevent even the smallest damage to the environment. At this moment digitalization allows us to get a complete picture of the value chain from the extraction of minerals to their shipment, providing a holistic view of the entire operation [4]. The collected data can be analyzed to identify production problems, manage inventory and quality, track production and asset performance, and understand and save resources and costs [5].

The first wave of digitalization connected disparate operations, corporate processes, and reporting through enterprise resource platforms (ERP). As a result of this consolidation, large investments in digital infrastructure have been made worldwide for communication in some cases in highly remote parts of production. At the same time, at the enterprise level, the production management system (MES) is a standard information network for tracking production and rework [6]. As the number of target workers in the mining industry decreases and it becomes more specialized and expensive, especially in developed countries, digital technologies are used to transmit information about operations to management and local workers, allowing better regulation of production and faster troubleshooting. Due to dangerous working conditions and environmental threats at mining sites, connected sensors, monitors and alarms have become key tools for collecting and transmitting messages about potentially dangerous incidents and conditions, as well as for quickly alerting employees and management of possible problems [7].

Digitalization, automation, and new technologies can provide operators and technicians with quick access to important information about productivity, work conditions, and technical equipment. This type of data speeds up decision-making, troubleshooting, increases efficiency, and provides better environmental protection [8]. In addition, digitalization provides safer working conditions, promotes interaction between production sites, and increases the attractiveness of work. In this regard, the following areas of development of digital technologies in the mining industry can be identified.

First, data, computing power, and connectivity. The introduction of a huge number of sensors into physical objects that produce large amounts of data for analysis and communication between machines is becoming more and more accessible. The staff 
receives a huge amount of data from the sensors, resulting in a more accurate and consistent picture of the actual conditions.

Secondly, analytics and advanced information capabilities. Advances in analytics help transform vast data sets into a representation of the probability of future events. Telecommunications companies, for example, use intelligent algorithms to predict customer behavior, and retail firms use them to generate targeted offers for customers. Mining tasks such as geological modeling, daily planning, and preventive maintenance are increasingly included in the domain of intelligent statistical and optimization algorithms.

Third, the digital transformation. Advances in robotics make fully autonomous equipment more affordable and efficient. Technological advances in areas such as artificial intelligence increase the complexity of robotics and expand its application. In the mining industry the use of remote-controlled and assisted monitoring equipment is becoming ubiquitous, and the introduction of fully autonomous equipment is taking root in transportation, drilling and other processes. All these technologies contribute to radical changes in the way mining is conducted. These changes are characterized by both the use of information flow to reduce inefficiency in decision-making, and the deployment of more centralized, mechanized operations to reduce the number of possible problems in implementing these solutions.

Digitalization can involve the development of a so-called digital double or digital copy that is created and developed simultaneously with the real machine. In addition, the introduction of digitization programs, such as cloud services, remote diagnostics of machines, and data analysis, can lead to the formation of new business models and opportunities in existing companies, as well as to the creation of completely new companies and concepts.

Thus, digitalization opens up opportunities to address the challenges that the mining industry still faces today. Mining companies need solutions that not only collect, visualize and analyze operational data, but also manage it on different sites.

\section{Results and Discussion}

To assess the advantages and disadvantages of digitalization, it is advisable to consider the potential of Russian Federation and its mining industry, as well as possible risks associated with this process.

Of course, in terms of the digitalization process monitoring and complex diagnostic equipment in real time will lead to improved planning and reduced downtime and hence lower costs for maintenance. The use of intelligent software and hardware modules for energy management links energy management with automation and thus ensures transparency of the mine's energy supply, resulting in efficient energy use and better cost control. A common database for engineering activities and documentation contributes to consistent data management, updating, reducing construction costs and time, and, consequently, increasing the uptime of equipment.

Digitalization will have the greatest impact if technologies are integrated into a single coal value chain. Currently, there are five areas of significant value formation.

First, a deep understanding of the resource base. The process of improving resource estimation, from exploration to short-term production planning, is related to various factors: the scale or area of work, data sources, and different geological models. Statistical methods that allow you to understand the exploration data can increase the probability of finding resources and ensure greater efficiency of preparatory and mining operations, and as a result get the most reliable information. Integration of geological data into one universal source of reliable information helps to optimize the parameters of work, allows us to create an ongoing production plan. 
Secondly, optimization of expenses on materials and equipment. In essence, mining value chains are interdependent systems consisting of several units of stationary and mobile equipment. Real-time data and modern analytical computer programs provide the ability to plan and process solutions that maximize the use of equipment and profit. The combination of traditional control with intelligent algorithms could optimize the movement of the machine to achieve maximum efficiency.

Third, improving the prediction of equipment failures. Mining companies usually collect huge amounts of data from working machines and equipment, but this information is rarely used to generate analytical estimates. Using this information in a digitalized environment to assess the probability of failure of specific components, instead of using the traditional current-time approach, helps reduce maintenance costs and prevent failures.

Fourth, the increasing mechanization at the expense of automation. Automation makes it possible to reduce operating costs, improve work discipline, improve environmental protection and ensure work safety. In addition, the development of mining automation reveals opportunities to reduce the number of employees working in the most dangerous areas.

Fifth, monitoring performance in real time and compare it with the plan. One of the advantages of collecting real-time data is an up-to-date picture of the condition and location of each piece of equipment during pre-production or mining operations in a specific time period, and an analysis of whether it is working as planned. This knowledge gives a new meaning to operations management, which is not about a monthly report, but about focusing on changes and compliance with the plan. In addition, real-time data transfer to the main operations center facilitates rapid management decision - making in the head office, which is able to take measures to optimize operations across the entire value chain.

Along with the listed advantages, it is worth noting the risks of digitalization of mining enterprises. First of all, this concerns the lack of use of automation tools for production processes, so the transition to digital technologies may take a long time. Thus, at the time of approval of the Program "Digital economy of Russian Federation", the business digitalization index for all types of economic activities was only 28.4 , and the same indicator for the activity "Mining" - 29.1, exceeding the industry average by only 0.7 points. Comparative analysis of the use of digital technologies for the same parameters and evaluation period (table.1) confirmed a similar correlation indexes.

Table 1. Comparative analysis of the use of digital technologies by economic entities of Russian Federation - in general by type of economic activity and in the extractive industry (in \% of the total number of organizations).

\begin{tabular}{|c|c|c|}
\hline Indicator & $\begin{array}{l}\text { Total by type } \\
\text { of activity }\end{array}$ & $\begin{array}{l}\text { Extraction } \\
\text { of minerals }\end{array}$ \\
\hline \multicolumn{3}{|l|}{ 1. Use of automated control systems } \\
\hline 1.1 Total & 24.6 & 29.3 \\
\hline 1.2 ERP- system & 19.2 & 25.6 \\
\hline 1.3 CRM- system & 13 & 12.5 \\
\hline 1.4 SCM- system & 7.1 & 8.2 \\
\hline \multicolumn{3}{|l|}{ 2. Using software tools } \\
\hline 2.1 EDM-system & 62.3 & 63.6 \\
\hline 2.2 For the implementation electronic form of financial accounts & 53.7 & 55.6 \\
\hline 2.3 To solve organizational, managerial and economic problems & 52.7 & 58.7 \\
\hline 2.4 Electronic legal reference systems & 50.4 & 63.2 \\
\hline 2.5 To manage purchases and sales of goods, works, and services & 41.0 & 34.9 \\
\hline 2.6 To provide access to databases through an information network & 27.5 & 24.0 \\
\hline $\begin{array}{l}2.7 \text { To manage automated production and / or separate technical } \\
\text { means and technological process }\end{array}$ & 20.1 & 38.1 \\
\hline 2.8 For design & 17.0 & 29.9 \\
\hline
\end{tabular}




\begin{tabular}{|l|c|c|}
\hline 2.9 Training program & 15.4 & 29.4 \\
\hline 2.10 For scientific research & 3.6 & 4.4 \\
\hline \multicolumn{2}{|c|}{ 3. Intensity of using digital technologies } \\
\hline 3.1 Broadband Internet & 81.5 & 85.5 \\
\hline 3.2 Cloud services & 22.6 & 17.4 \\
\hline 3.3 RFID-technology & 6.2 & 10.2 \\
\hline 3.4 Electronic sales via websites & 12.3 & 6.9 \\
\hline
\end{tabular}

Thus, automated production control systems are used by about $30 \%$ of mining enterprises, while the most common ones are ERP-systems; being corporate control systems in nature, they are used by large mining enterprises, which can allow significant financial costs for their acquisition and adaptation. In comparison with economic entities in other sectors of the economy, which was calculated averages, the mining enterprise to a much greater extent using software control automated manufacturing and / or separate technical means and technological process (share of companies using them is more than 38 $\%$, which is almost 2 times higher than average), as well as for design of certain types of works (almost $30 \%$, which is 1.8 times more than the average in the industry).

Equally serious are the problems of ensuring the security of computer networks. Horizontal and vertical integration of all network levels, connection of automation networks with IT networks, and use of the Internet for remote maintenance and diagnostics can lead to security violations of access to information by unauthorized persons, to spying and data manipulation, as well as to damage and loss of data through malware. The consequences of this can be very serious, including death, injuries, environmental damage, and financial losses.

Comparative analysis of using information security tools at the time of adoption of the Program "Digital economy of Russian Federation" (table.2), showed that in almost all comparable parameters, mining companies pay more attention to data protection.

Table 2. Comparative analysis of the use of information security tools by economic entities of Russian Federation - in general by type of economic activity and in the extractive industry (in \% of the total number of organizations).

\begin{tabular}{|l|c|c|}
\hline \multicolumn{1}{|c|}{ Indicator } & $\begin{array}{c}\text { Total by type } \\
\text { of activity }\end{array}$ & $\begin{array}{c}\text { Extraction } \\
\text { of minerals }\end{array}$ \\
\hline 1. Regularly updated anti-virus software & 87.8 & 92.8 \\
\hline 2. Means of electronic digital signature from & 83.7 & 79.4 \\
\hline $\begin{array}{l}\text { 3. Software hardware that prevents malicious programs } \\
\text { accessing it }\end{array}$ & 64.8 & 77.0 \\
\hline 4. Technical means of user authentication & 64.6 & 68.6 \\
\hline 5. Strong authentication tools & 61.4 & 70.9 \\
\hline 6. Spam filters & 59.3 & 60.4 \\
\hline 7. Encryption tools & 51.3 & 54.6 \\
\hline 8. Tools for detecting computer network intrusion & 45.0 & 51.0 \\
\hline $\begin{array}{l}\text { 9. Software tools for automating the processes of analysis and } \\
\text { control of computer system security }\end{array}$ & 34.9 & 40.5 \\
\hline $\begin{array}{l}\text { 10. Backup data to media that is not physically located on the } \\
\text { organization's territory }\end{array}$ & 30.7 & 32.6 \\
\hline 11. Biometric authentication of the user & 5.7 & 7.5 \\
\hline
\end{tabular}

However, in order to eliminate the above-mentioned threats in the context of digitalization of production, it is necessary to strengthen the control of protection against access to the computer network (about $51 \%$ of mining enterprises are used) and the protection of computer systems (40\%). 
An additional risk factor for digitalization may be the insufficient level of professionalism of personnel to work with digital technologies, since at the time of approval of the Program, Russia was in the 30th place in terms of the share of information and communication technology specialists with both intermediate and higher qualifications, with indicators of 0.3 and $1.2 \%$, respectively (Fig.1).

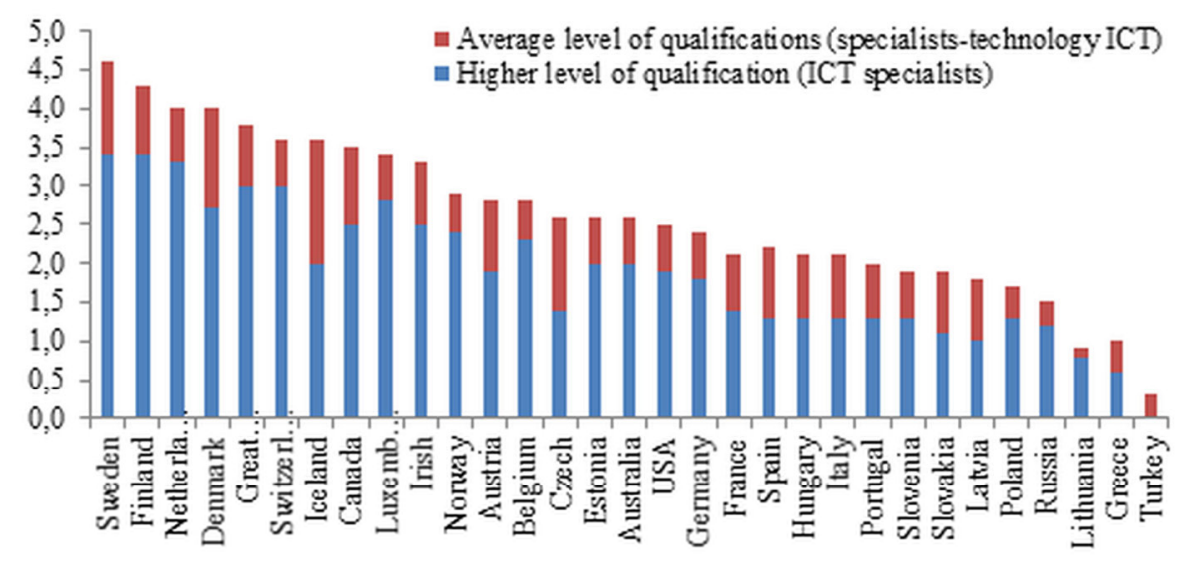

Fig. 1. Percentage of ICT professionals in total employment by skill level and country, \%.

According to the results of the self-assessment procedure, out of 8 holding companies in the mining industry of Kemerovo region - Kuzbass, by the end of 2018, 2 ones demonstrated the maximum readiness for digitalization (that is, these structures are in the process of transitioning to digital management systems or may begin the transition within the next 3 years), but 9 enterprises of them will gradually introduce technologies lagging behind others [5]. Among the digital technologies that have the highest level of implementation or are planned for implementation in 2019-2020, the following are highlighted: "Remote video transmission, video conferencing, and wireless communication with workers"; "Mining dispatching system based on the Industrial Internet of things (sensors and equipment in production are integrated into a single network by a hierarchical structure and are subject to a single production management system)"; "Automated system for managing, accounting and controlling the volume of pollutants released»; "Digital modeling, virtual mine / cut" (3D model) in design and operational management"; "BigData, predictive analysis, neurotechnology and artificial intelligence in data processing, machine learning (for example, when analyzing geological conditions or mining technologies)".

\section{Conclusion}

Creating digital platforms for managing the mining industry is a strategically important task that can not only restore material production, lay the foundation for future innovations, but also ensure the further development of Russian Federation.

Currently, digital transformation in the mining industry is present at the level of large holdings, with a delay in implementing the principles of digitalization in their individual structures and applying certain elements of digital technologies. To achieve maximum effect, it is necessary to create appropriate conditions for the development of a new technological order, justify rules that promote the protection of information in the context of digitalization and the use of digital technologies, identify skills that allow employees to benefit from the opportunities of the digital economy, as well as provide training for 
personnel with the appropriate level of knowledge, skills and skills in both information and communication technologies and mining. To ensure production security, network security and system integrity, it is necessary to ensure the reliability of equipment operation, as well as the safety of personnel through user authentication and administration, information management, and timely detection of attacks.

\section{References}

1. T. Tyuleneva, Mining, Intelligent Equipment and Environment Protection conference proceedings, 1, 10 (2018)

3. U. Khadam, M. M. Iqbal, M. A. Azam, S. Khalid, S. Rho, N. Chilamkurti, Digital watermarking technique for text document protection using data mining analysis, 7, 23 (2019)

4. A. Encalada, C. Orellana Fantoni, C. Vaca, J. Gorotiza, N. Pilco, Digital transactions mining to characterize temporal rhythms of a city, 2019 6th International Conference on eDemocracy and eGovernment, 6, 1 (2019)

5. J. Fernández-Lozano, A. González-Díez, J. Remondo, J. Bonachea, M. Morellón, G. Gutiérrez-Alonso, J. García-Talegón, G. Alonso-Gavilán, R.M. Carrasco, J. Pedraza, Minerals, 11, 37 (2018)

6. L. Samorodova, L. Shut'ko, Yu. Yakunina, O. Lyubimov, P. Kovacs, E3S Web of Conferences, 141, 040012 (2019)

7. G. V. Kalabin, V. I. Gorny, S. G. Kritsuk, Journal of Mining Science, 2, 35 (2016)

8. A. Kopytov, V. Pershin, E3S Web of Conferences, 141, 01010 (2019) 